\title{
RESPUESTA DE LA FERTILIZACIÓN CON BORO EN EL CULTIVO DE ALFALFA Medicago sativa SANTA ROSA DE CUSUBAMBA- CAYAMBE
}

\author{
* Nelson Guaytarilla \\ **Freddy Daquierdo Cadena
}

\section{INTRODUCCIÓN}

Las praderas naturales e introducidas, constituyen el renglón más importante y económico para la nutrición de ganado bovino en el Ecuador. La intensificación de las explotaciones de ganado lechero, principalmente en la Sierra, obligan a un constante mejoramiento de las pasturas, como principal fuente de alimento para los rumiantes lecheros, ya que sin ellas la intensificación de las explotaciones resulta inútil y antieconómica. Se hace necesario entonces mejorar el manejo de esta valiosa forrajera y una alternativa constituye la utilización del fertilizante químico boro y los niveles exactos que requiera esta forrajera, para que ofrezca mejores rendimientos, lo que finalmente se reflejará en el incremento de la producción de leche y los ingresos percibidos por la venta de este alimento de primera necesidad. Entre los objetivos tenemos: establecer la eficiencia del boro en la producción del cultivo de Alfalfa destinada a la alimentación del ganado vacuno, determinar el efecto producido por las diferentes dosificaciones de Boro en la producción del cultivo de alfalfa, realizar el análisis económico para cada una de las dosificaciones en la producción de alfalfa.

\section{REVISIÓN BIBLIOGRÁFICA ORIGEN}

Nativa del sudoeste de Asia (Asia Menor), se sabe que fue cultivada por primera vez en las tierras del actual Irán y llevadas a Grecia hacia el 490 a.C., luego pasó a los países europeos y fue traída a América por españoles durante la conquista.

\section{DESCRIPCIÓN BOTÁNICA}

Su raíz es axonomorfa y puede llegar hasta $9 \mathrm{~m}$ de profundidad, los tallos son erectos, generalmente entre 60 y $90 \mathrm{~cm}$ que surgen de la corona leñosa en la base de la planta, los nuevos brotes de tallo nacen de esta corona cuando los tallos maduran o son cortados; las hojas son pinadas trifoliadas arregladas alternativamente en el tallo y de color verde intenso, en los medicagos como la alfalfa, la lámina central de la hoja tiene el pecíolo más largo que las dos láminas laterales. Las flores son papilionáceas, se estructuran en racimos sueltos de color violeta, amarillo y en algunos casos blanco. La semilla se presenta en vainas y en forma espiral.

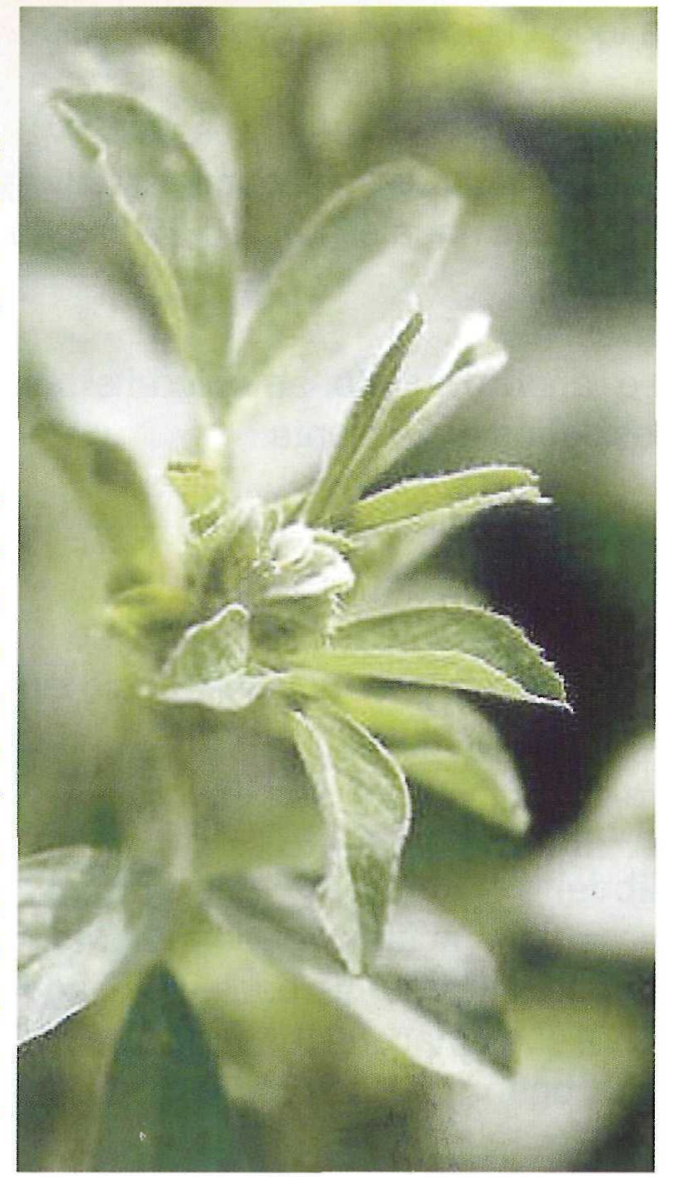




\section{CONDICIONES DEL CULTIVO}

La temperatura, según las variedades, el rango óptimo es de $18-28^{\circ} \mathrm{C}$. El factor limitante en el cultivo de la alfalfa es la acidez; el pH óptimo del cultivo es de 7.2, recurriendo a encalados siempre que el $\mathrm{pH}$ baje de 6.8. Además los encalados contribuyen a incrementar la cantidad de iones de calcio en el suelo, disponible para la planta y reducir la absorción de aluminio y manganeso que son tóxicos para la alfalfa. Esta es muy sensible a la salinidad, cuyos síntomas comienzan con la palidez de algunos tejidos, la disminución del tamaño de las hojas y finalmente la parada vegetativa con el consiguiente achaparrado. El incremento de la salinidad induce desequilibrios entre la raíz y la parte aérea.

\section{Tipo de suelos}

La alfalfa requiere de suelos profundos y bien drenados, aunque se cultiva en una amplia variabilidad de suelos; estos con menos de $60 \mathrm{~cm}$ de profundidad no son aconsejables para su cultivo.

\section{Nitrógeno}

Se debe abonar $20 \mathrm{~kg} / \mathrm{ha}$ de nitrógeno, pues cantidades mayores producirán un efecto negativo al inhibir la formación de nódulos.

\section{Fósforo}

En alfalfares de regadío con suelos arcillosos y profundos, la dosis de P205 de fondo para todo el ciclo de cultivo es de 150-200 kg/ha.

\section{Potasio}

En suelos pobres se recomienda un abonado potásico de fondo de 200-300 kg/ha y restituciones anuales de $100-200 \mathrm{~kg} / \mathrm{ha}$.

\section{Azufre}

Si se añade sulfato amónico, el suelo se enriquece lo suficiente para cubrir las necesidades de la planta.

\section{Boro}

Se trata de una carencia muy usual en el cultivo de la alfalfa, ocasionando la detención del crecimiento, amarillamiento de las hojas terminales y escaso crecimiento entre nudos. Para enriquecer el suelo en este elemento se mezcla con otros abonos que facilitan su distribución. Se debe tener en cuenta que los encalados suelen agravar la situación de escasez de Boro.

\section{Molibdeno}

Los suelos ácidos pueden presentar carencia de molibdeno, que afecta al funcionamiento de las bacterias fijadoras de nitrógeno. Cuando es preciso añadirlo al terreno, suele hacerse en forma de molibdato sódico o amónico. 
Siempre es importante saber escucharoo

\section{Enmiendas calizas}

Son materias fertilizantes que contienen calcio y magnesio en forma de óxidos, hidróxidos o carbonatos. La finalidad de la enmienda cálcica es mantener o incrementar el pH del suelo, así como mejorar sus propiedades.

\section{CARACTERÍSTICAS DE LA SIEMBRA Preparación del terreno}

Antes de realizar la siembra es necesario conocer las características del terreno, contenido de fósforo y potasio, condiciones de drenaje y el $\mathrm{pH}$.

Las labores de preparación del terreno se inician con un subsolado (para remover las capas profundas sin voltearlas ni mezclarlas) que mejorará las condiciones de drenaje y aumentará la capacidad de almacenamiento de agua del suelo.

Esta labor es muy importante en el cultivo de la alfalfa, pues las raíces son muy profundas y subsolando se favorece que estas penetren con facilidad. A continuación se realizan sucesivos gradeos de 2 a 3 , con la finalidad de nivelar el terreno, disminuir el encharcamiento debido al riego o a intensas lluvias y eliminar malas hierbas existentes.

Se recomienda intercalar las labores con aplicaciones de abonos y enmiendas realizadas al mismo tiempo que los gradeos, para mezclar los fertilizantes con la tierra y homogeneizar su distribución.

Conviene aplicar el abonado de fondo y el encalado dos meses antes de la siembra para permitir su descomposición y estar a disposición de la plántula después de la germinación.

\section{VALOR NUTRICIONAL}

En la siguiente tabla se muestra la composición de la materia seca de hojas y tallos.

Características bromatológicas de la alfalfa:

\begin{tabular}{|c|c|c|}
\hline$\%$ & HOJAS & TALLOS \\
\hline Proteina bruta & 24 & 10.7 \\
\hline Grasa bruta & 3.1 & 1.3 \\
\hline Extracto no nitrogenado & 45.8 & 37.3 \\
\hline Fibra bruta & 16.4 & 44.4 \\
\hline Cenizas & 10.7 & 6.3 \\
\hline
\end{tabular}

El aporte de agua en caso de riego por inundación es de $1000 \mathrm{~m}^{3} / \mathrm{ha}$. En riego por aspersión será de $880 \mathrm{~m}^{3} / \mathrm{ha}$.

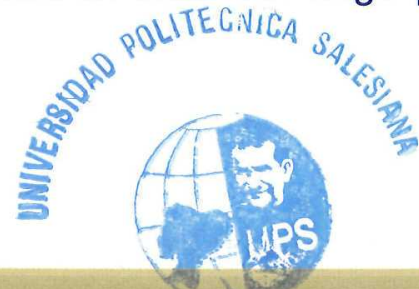




\section{IMPORTANCIA DEL BORO EN EL CULTIVO DE ALFALFA}

El boro se encuentra en la mayor parte de los suelos en cantidades extremadamente pequeñas, oscilando generalmente desde aproximadamente 20 a 200 partes por millón. El boro no se halla normalmente en cantidades tóxicas en los suelos arables, a menos que haya sido añadido en exceso en los fertilizantes comerciales. La mayor parte del boro disponible en el suelo es suministrado por la fracción orgánica. Cuando se descompone la materia orgánica se libera el boro, y va una parte a las plantas y otra se pierde por filtración.

El fertilizante en boro más conocido es el bórax que contiene el 10,6 \% de boro y es un compuesto blanco hidrosoluble. La dosis a emplear variará entre uno y dos kilos por hectárea. Es uno de los microelementos más ampliamente aplicado. Especialmente en la alfalfa, actúa en los meristemas de la planta (tejidos de crecimiento), en las hojas jóvenes y en la yema terminal o punto vegetativo.

\section{Dosis de Aplicación}

La dosis del fertilizante Rey Alfalfa que se va a utilizar es $150 \mathrm{~kg} / \mathrm{ha} / \mathrm{año}$.

\begin{tabular}{|c|c|c|c|c|}
\hline & DosıS 1 & DOSıS 2 & Dosıs 3 & Dosıs 4 \\
\hline Fertilizante & $\mathrm{kg} / \mathrm{ha} / \mathrm{año}$ & $\mathrm{kg} / \mathrm{ha} / \mathrm{año}$ & $\mathrm{kg} / \mathrm{ha} / \mathrm{año}$ & $\mathrm{kg} / \mathrm{ha} / \mathrm{año}$ \\
\hline $\mathrm{N}$ & 18 & 18 & 18 & 18 \\
\hline $\mathrm{P}$ & 36 & 36 & 36 & 36 \\
\hline $\mathrm{K}$ & 18 & 18 & 18 & 18 \\
\hline Mg & 6 & 6 & 6 & 6 \\
\hline S & 4.5 & 4.5 & 4.5 & 4.5 \\
\hline B & 0 & 1.395 & 2.79 & 5.58 \\
\hline
\end{tabular}

\section{BIBLIOGRAFÍA}

INTERNET www. Infoagro. com

INTERNET www. nitragin. Com.ar

INTERNET www. gro.intem.Mx

IZQUIERDO, Freddy: Guía de estudios Pastos y Forrajes I. Universidad Politécnica Salesiana. Cayambe. 2001, pp 8-10.

MUÑOZ, Carlos: Guia de estudios de suelo II. Universidad Politécnica Salesiana. Cayambe. 2003, pp 10-11.

BENÍTEZ, A.: Pastos y Forrajes. Editorial Universitario. Quito. 1980, pp 179-183.

CALLES, C.: Respuestas de la alfalfa a la fertilización. Tesis Ing. Agr. Universidad Central del Ecuador. Facultad dce Agronomía. Quito. 1964, pp 26-30.

POZO, M.: La alfalfa su cultivo y aprovechamiento. Castell Ediciones. Mundi Prensa. 1971, pp 18-170.

* Nelson Guaytarilla, Tesista de la Carrera de Ingenieería Agropecuaria - Cayambe

* * Freddy Izquierdo Cadena, Catedrático de Pastos y Forrajes, Director de Tesis. 